\title{
Incorporating SMEs in the Capital Market of Bangladesh: Obstacles, Initiatives and Potentials
}

\author{
Dr. Razia Khatun ${ }^{1} \quad$ Md. Amanullah ${ }^{2 *}$ \\ 1.Professor of Economics, Department of Humanities, Khulna University of Engineering \& Technology, Khulna, \\ Bangladesh \\ 2.Lecturer of Management, Department of Humanities, Khulna University of Engineering \& Technology, \\ Khulna, Bangladesh
}

\begin{abstract}
The Stock Exchanges of Bangladesh have initiated a new window for small and medium enterprises so that they can get finance by issuing securities. Though $80 \%$ of the business in Bangladesh are SMEs, which are responsible for $25 \%$ of nation's GDP and $35.49 \%$ of the total workforce, limited access to formal financing impedes their effective operations and long-term growth. As a new platform, the insights related to obstacles of listing and fundraising, regulatory issues, and the future potentials remain uncovered due to lack of research initiatives. This study addresses these insights by analyzing both primary and secondary data. The study findings outline that SMEs now have the opportunity to trade-off between loans from creditors and financing by issuing securities. The decision mostly depends on whether a firm has enough collateral to avail loan from creditors, or it is prepared enough with proper documentation, standard books of accounts and regulatory issues of the capital market. While estimated fundraising costs through the capital market stand at $0.6 \%$ to $1.03 \%$, banks and financial institutions charge $13 \%$ to $17 \%$ for interest along with $1 \%$ to $2 \%$ for processing fees and stamp duty. However, the capital market demands limited liability company, asset valuation, standard books of accounts, tax filing, reporting and disclosure issues. The regulators have developed the platform as a learning ground by following 'Go Easy' principles so that the SMEs can exercise reporting and governance issues, and contribute to institute a transparent and sustainable capital market in the future.
\end{abstract}

Keywords: SME, financing, capital market, small capital platform, stock exchange

DOI: $10.7176 / \mathrm{JESD} / 12-2-03$

Publication date: January $31^{\text {st }} 2021$

\section{Introduction}

Small and Medium Enterprises (SMEs) are considered as blood of an economy. $80 \%$ of the business organization of Bangladesh are SMEs that comprise 35.49\% of the total workforce (Star Business Report 2019). In 2019-2020 FY, these establishments have contributed 25\% to the GDP of Bangladesh (Uddin 2019). However, the scope of the SME sector is yet to explore considering its contribution to neighbouring economies.

The stock market of Bangladesh could not produce positive outcomes in the past two years. Between 1st January 2018 and 25th March 2020, the broad index of Dhaka Stock Exchange (DSE), the prime bourse of Bangladesh with approximately $95 \%$ of the market capitalization, has decreased by $35.913 \%$ (Dhaka Stock Exchange [DSE] n.d.). Total turnover has also decreased significantly (34.02\%) in the aforesaid period (DSE, n.d.). Besides, the investors or group of investors have appeared in demonstration, human chain and other modes of protests for several times including 14th January 2020, 25th April 2019, and 20th May 2018 against the bourses, Bangladesh Securities and Exchange Commission (BSEC), government or alike stakeholders. These demonstrations express lack of confidence among the investors.

Despite the downturn and limitations of the concerned stakeholders, the Exchange has initiated Small Capital Platform (SCP) with a hope that it will escalate formal financing opportunities and ensure long-term growth of SMEs. SCP has also initiated to familiarize transparency and standard corporate practices which may bring a breakthrough in the history of the capital market of Bangladesh in the long run.

\subsection{Recognition of SME}

Bangladesh Bank (BB), the central bank of Bangladesh, and Ministry of Industries (MoI) of Bangladesh have identified the SMEs considering the size of capital, legal entity and number of employees engaged in the firm. The differences of SME recognition of BB, MoI and SCP as defined in BSEC (Qualified Investors Offer by Small Capital Companies [QIO by SCC]) Rules, 2018 are stated in the following table; 
Table 1. Definition of SME according to BB and SCP (amount in million BDT)

\begin{tabular}{|c|c|c|c|c|c|}
\hline Particulars & Type of Business & Small & Medium & $\begin{array}{l}\text { Defined } \\
\text { Authority }\end{array}$ & SCP (SME) \\
\hline $\begin{array}{l}\text { Size of } \\
\text { capital }\end{array}$ & $\begin{array}{l}\text { Service \& Business } \\
\text { Industrial }\end{array}$ & $\begin{array}{c}0.05 \text { to } 5 \mathrm{mn} \\
0.05 \text { to } 150 \mathrm{mn}\end{array}$ & $\begin{array}{l}5 \text { to } 100 \mathrm{mn} \\
15 \text { to } 200 \mathrm{mn}\end{array}$ & \multirow{3}{*}{$\mathrm{BB}$} & 50 to $300 \mathrm{mn}$ \\
\hline $\begin{array}{l}\text { Number of } \\
\text { employees }\end{array}$ & $\begin{array}{l}\text { Service \& Business } \\
\text { Industrial }\end{array}$ & $\begin{array}{l}25 \\
50 \\
\end{array}$ & $\begin{array}{c}50 \\
150 \\
\end{array}$ & & Not Defined \\
\hline Legal entity & \multicolumn{3}{|c|}{ Not a public limited company } & & $\begin{array}{c}\text { Public limited } \\
\text { company }\end{array}$ \\
\hline $\begin{array}{l}\text { Size of } \\
\text { capital }\end{array}$ & $\begin{array}{l}\text { Service } \\
\text { Manufacturing }\end{array}$ & $\begin{array}{c}1 \text { to } 20 \mathrm{mn} \\
7.5 \text { to } 150 \mathrm{mn}\end{array}$ & $\begin{array}{l}20 \text { to } 300 \mathrm{mn} 150 \\
\text { to } 500 \mathrm{mn}\end{array}$ & \multirow{3}{*}{ MoI } & 50 to $300 \mathrm{mn}$ \\
\hline $\begin{array}{l}\text { Number of } \\
\text { Employees }\end{array}$ & $\begin{array}{l}\text { Service } \\
\text { Manufacturing }\end{array}$ & $\begin{array}{c}16 \text { to } 50 \\
31 \text { to } 120\end{array}$ & $\begin{array}{c}51 \text { to } 120 \\
121 \text { to } 300\end{array}$ & & Not defined \\
\hline Legal Entity & \multicolumn{3}{|c|}{ Not Applicable } & & $\begin{array}{l}\text { Public limited } \\
\text { company }\end{array}$ \\
\hline
\end{tabular}

Source: Bangladesh Bank (n.d.); Ministry of Industries (2016)

\section{Research Objectives}

The general objective of the study is to examine the insights of fundraising and listing the SCP of Bangladesh capital market. The specific objectives are:

1. To determine the shortcomings of SMEs to get listed in SCP of the Exchange of Bangladesh

2. To analyze the regulatory drawbacks and matter(s) of discomfort in raising fund from SCP.

3. To investigate the initiatives already taken to address the matter(s) of discomfort and exploring the opportunities of SCP in Bangladesh so far.

\section{Literature Review}

SMEs are responsible for significant economic viability and contribution to a country's GDP. For this reason, SMEs are recognized as the key driver of speeding up the world's economy and introducing industrialization on a large scale (Muriithi 2017). The SMEs are also remarked as the engine of growth and equitable advancement of an emerging economy (Agwu 2014). Despite the importance of SMEs in economic viability and sustainable development of the world economies, the most burning issue of SME business is the restricted access to formal financing. SMEs are experiencing the same problem all over the world. A survey, which was conducted by the World Bank (WB) in more than a hundred countries during ten-year period, concluded that the financial constraint is the most significant limitation of SME growth and business operations (Beck \& Cull 2014). Researchers have successfully marked that the limitation of SMEs to access formal financing is the most important reason for restricting the endurance and development of SME business in Africa (Muriithi 2017). Muriithi (2017) specifies that the unavailability of formal financing option is the unanimously acknowledged hindrance of SMEs. The same problem is also specified in Nigeria (Agwu 2014). Hence, the restricted financial support is the main limitation of SMEs across the globe.

As a developing country, Bangladesh has also experienced the same financial burden that restricts the SMEs to grow and make the business sustainable. Alauddin \& Chowdhury (2015) state that financing limitation is the main hindrance of SME business progression in Bangladesh. Ahmed (2001) concludes that the restricted accessibility of institutional financing is the most severe constraint of the SMEs to grow. WB (2019) has identified several remarkable weaknesses of financial infrastructure for Micro, Small and Medium Enterprise (MSME) credit in Bangladesh in the year 2018. Besides, $46 \%$ of the SMEs get personal financing, among which $21 \%$ seek for financial assistance from family or friends (Islam et al. 2005). Hence, a significant percentage of SMEs are out of formal financing opportunities.

Though the SMEs have the least degree of formal financing opportunities, it is not always for the unavailability of financial intuitions (FIs) or interests of the FIs. The SMEs are also responsible for a great deal for the restricted scope of formal financing. In many cases, the SMEs do not maintain proper transaction records or books of accounts; even sometimes they do not record the business activities at all (Basil 2005). Rogers (2002) prescribes that poor maintenance of record and ineffective business operations are the primary characteristics of maximum SMEs. The lack of proper records of business activities and maintenance of books of accounts leads the FIs to reluctant from sanctioning loans to the SMEs. Furthermore, the performance evaluation of the business operations cannot be assessed due to the lack of systematic preparation of books of accounts resulting in maladministration and the downfall of the organization (Agwu 2014). Hence, the SMEs get themselves restricted to flourish formal financing opportunities due to their won causes: lack of systematic record-keeping, preparation of books of accounts as per standard practices and inefficiency in overall business operations.

Public appearance is another important success factor of today's competitive world as it reduces uncertainty. 
The stakeholders-customers, investors, talent personnel, creditors and others-must have confidence in the business operations of the organization to which they want to engage. Unfortunately, the SMEs have a little public appearance; therefore, the stakeholders do not want to engage so much due to lack of confidence. Muriithi (2017) states that the negative outlook of prospective customers creates a big challenge for SMEs. The customers think that small-scale business organizations are not able to offer good quality products and services (Amyx 2005). The SMEs have experienced a lack of confidence and uncertainty due to the unavailability of information to the public. Hasan \& Jamil (2014) have specified that unlike the larger corporations, the SMEs do not appear in public; while the availability of information reduces the level of uncertainty. Moreover, it is established that issues related to uncertainty reduce the financing opportunity of SMEs (Hasan \& Jamil 2014). For this reason, the SCP may be a potential ground for SMEs to uplift stakeholders' confidence as the companies listed in the stock exchange must disclose the financial and operational information to the public.

Transparency and good governance are great concerns for investors and creditors. Auditing is the most widely accepted mechanism to ensure transparency and governance of an organization's activities. The public limited companies registered as per The Companies Act, 1994 require to conduct an obligatory audit of their books of accounts and cost audit (for certain industries) by external audit farm(s) certified by the concerned authority. However, many small and medium scale firms neither entitle to auditing of their books of accounts nor publish the information to the public; in result, this malpractice reluctant bankers to sanction credit to the SMEs (Hasan \& Jamil 2014). Hence, the SMEs get themselves stuck in accessing formal financing opportunities from creditors especially banks and FIs due to question of transparency and governance issues.

Banks and FIs impose several restrictions like collateral requirements, high rate of interest and inaccessibility to long-term credit, and takes a significant amount of time (4 to 6 months) before sanctioning credit (SME Foundation 2019). In addition, most of the SMEs seek for or FI's sanction for financing the working capital, while long-term financing is required for growth and development (The World Bank n.d.). Hence, quality sources of long-term financing are evident to ensure sustainable growth of SMEs.

The problems and opportunities of SMEs in Bangladesh economy have stated in different research initiatives primarily focusing on internal limitations, restricted credit accessibility, resource constraints for effective business function and others. Though literatures have communicated the operating problems and potentials of small-scale entities in Bangladesh, there are no significant research on insights of SMEs to get listed and raise fund through the capital market platform. This study addresses the research gap by articulating listing and fundraising obstacles of SMEs and their possibilities in the SCP of Bangladesh.

\section{Methodology}

Both primary and secondary sources of data are collected and analyzed to conduct this study. The primary data are collected through open discussion and/or telephone conversation from representatives of Exchange, an issue manager, a credit rating agency and 15 SMEs that are interested in fundraising through the SCP. The problems identified from the discussions are discussed with 2 experts in the field to articulate the potentials of SMEs in the capital market of Bangladesh.

Secondary sources of data are collected from a number of related literatures, several rules and regulationsBSEC (QIO by SCC) Rules, 2016; BSEC (QIO by SCC) Rules, 2018; BSEC (Public Issue) Rules, 2015; DSE (Listing of SCC) Regulations, 2019-national industrial policy of MoI, and SME credit policy of BB. Several other documents from secondary sources like SME Foundation, business magazine, national daily and others are also considered for the study.

The collected data are analyzed by following narrative data analysis technique. The conversation or discussion scripts are assigned as selective coding including financing, cost, time, reporting and disclosure issues, capital formation, documentation, risk, transparency and governance, and others. The coded data are then summarized to get meaningful insights.

\section{Problems Related to Fund Raising and Listing of SMEs in SCP}

\subsection{Existing Limitations of SME Financing}

Banks and FIs are the primary financing options for financing the business. However, SMEs have only limited access to those institutions around the world. For example, bank lending serves more than $90 \%$ of the large corporations, but it serves only 20\% of the SMEs in China (Xiaojin 2019). In 2018, MSMEs opted a recorded amount of loan of RMB 26 trillion $(\approx 3.7$ trillion USD), which is only $32.1 \%$ of the total enterprise loan balance (Xiaojin 2019).

MSMEs also experience restricted availability to get finance from designated creditors in Bangladesh. World Bank Group [WBG] (2019) has reported a total deficit of BDT 23,700 Cr in SME financing in 2019. WBG (2019) also reported that only $27.5 \%$ of MSMEs have the access to formal financing, while large corporations receive $44 \%$ institutional financing opportunities. In many cases, the institutions are willing to finance the MSMEs but the MSMEs cannot fulfil the collateral requirement imposed by the banks and FIs. Moreover, the start-up MSMEs do 
not generally have such collateral to deposit in the creditor's vault.

\subsection{Incorporating as Public Limited Company}

The capital market is the platform for raising capital by issuing debt or equity securities. To do so, the entity must be registered as a public limited company. An organization has to comply several formalities and pay a significant amount of fees to get registered as a public limited company. For this reason, most of the SMEs incorporate as sole-proprietorship, partnership or private limited company. In this case, to raise capital by issuing securities, a firm requires to convert itself into a public limited company. Many SMEs do not feel comfortable in converting the firm to a public limited company because the process must comply with the Companies Act, 1994 and other procedures of the Registrar of Joint Stock Companies and Firms (RJSC). Moreover, after incorporating as a public limited company, it has to follow several corporate governance and compliance issues. However, in most of the cases, it's not the fear of compliance or corporate governance issues, the complexities of laws or law enforcing authorities, costs associated with compliances and lack of proper knowledge regarding standard business practices elevate the fear. Almost all the SMEs ask the same question that why they should walk through the complexities of corporate governance instead of simple business practice with debt financing.

\subsection{Subordination of Ownership Claim}

Many SMEs want to raise the fund but do not want to share the ownership. Chiefly, this tendency is acute in the case of family-based business. As a result, they are not in comfort zone either to incorporate the firm as a public limited company or to raise funds from the capital market platform by subordinating their ownership claim. In most of the cases, instead of subordinating their ownership claim, they opt for debt capital from banks and other FIs without cross-examining the costs and benefits associated with debt and equity financing.

\subsection{Bringing up Pre-issue Paid-up Capital}

The SMEs generate a huge amount of turnover by using the personal assets of the entrepreneur(s). Once, the entrepreneurs or promoters decide to incorporate the firm as a public limited company, they first experience the burden of converting personal assets (especially land and building) to the firm. In Bangladesh, the conversion of land and building requires a huge amount of time. The firm also requires to pay capital gain tax, registration or conversion fee, stamp duty and local government tax (total $9.5 \%$ of the value) on land and building (The Finance Today 2020). An issue manager prescribes that it takes about a year and more than BDT 2 Million for documentation and conversion of assets. These reasons are also responsible for discouraging the entrepreneurs for raising capital from capital market.

\subsection{VAT and Tax Documentation}

Though SMEs are the key player of the national economy of Bangladesh, they are very much unorganized in operating their activities. Many SMEs do not properly maintain VAT or Tax documentation, even if they pay VAT or Tax. Once, the firm intends to incorporate in the capital market as a public limited company and start preparing books of accounts, it has to submit the deferred tax from its date of incorporation as a business entity. In this regard, the SMEs experienced that instead of producing VAT and Tax documents, they can be financed by debt capital.

\subsection{Asset Valuation}

Most of the SMEs operate their operations successfully and profitably with a huge amount of turnover. However, their turnover amount is completely inconsistent with their capital formation for not conducting valuation of assets and business in the recent period. As the SME platform of the capital market of Bangladesh requires minimum paid-up capital (post-issue) of BDT 50 million, the firm has to produce valuation report that requires time and costs. In fact, without producing valuation report in recent years, the promoters or sponsors of the firm will lose their proportionate claims on the business. Hence, asset valuation is an essential part for incorporating in the SCP of the stock exchange.

\subsection{Auditing and Preparation of Financial Statements}

Most of the SMEs, other than Limited Liability Company, record the transactions only for identification of income, expense, profit or loss of the business. They do not bother about preparing the financial statements following the guidelines of standard accounting practices like IFRS or IAS. For preparing prospectus, the firm requires to prepare its financial statements according to IFRS or IAS. The statements must be audited according to ISA. Many SMEs do not want either to embrace the hustle or to bear the costs associated with auditing and preparation of financial statements as per international standards, while they can get easy credit from the financial institutions by showing the general accounts comprises the records of transactions.

The capital market platform makes it obligatory that the companies want to get listed in the Exchange and to raise capital by issuing securities must submit audited financial reports for a specific period (BSEC 2015.). The 
SCP of the Exchange of Bangladesh also imposes the same restriction to ensure transparency. As per section 4(c) of BSEC (QIO by SCC) Rules, 2018, an SME that wants to raise capital through SCP of the Exchange must apply along with audited financial reports of not older than 120 days (BSEC 2019). According to section 135 of the Companies Act, 1994, the company should present the financial information in the prospectus (Ministry of Commerce n.d.). For this reason, the SMEs that do not maintain their books of accounts as per standard practices like IFRS or IAS, or perform auditing of their accounts according to ISA cannot participate in the SCP for equity capital.

\subsection{Fear of Post-Issue Disclosure and Reporting Requirements}

The capital market imposes some compliance issues to the companies for ensuring transparency and protecting investors' rights. The prospective issuer fears that the Exchange and BSEC are going to impose rigorous reporting and disclosure obligations. A greater extent of anxiety has been observed in case of SMEs since most of them are not concerned much about preparing the books of accounts according to standards and disclosing the results to the stakeholders especially to the outsiders. In addition, the presentation of the BSEC or the Exchange regarding noncompliance of reporting and disclosure issues, and, in certain cases, the representation of media in a negative mode causes a negative perception to the prospective issuers to be listed in the stock exchange. The fear negatively affects a greater extent to the small and medium sized entities.

\subsection{Cost of Fund Raising and Listing}

Cost of fundraising is one of the deepest concerns of SMEs. Since SMEs have a small scale of operations with lower turnover compared to the large-sized entities, the higher costs of fund-raising lead to the low rate of Return on Investment (ROI). However, in the case of small and medium-sized entities, the initial costs of fundraising from SCP are lower than the other sources (i.e. credits from banks or FIs) if the enterprise has no significant deferred expenses such as Tax and VAT. In an estimate considering no deferred expenses and zero costs for changes in existing capital structure, it is observed that SMEs have to incur $1 \%$ to $2 \%$ for debt financing and $0.60 \%$ to $1.03 \%$ for equity financing (Abdullah 2020). Banks and FIs also incur 13\% to 17\% interest rates on debt financing (Uddin 2014). The cost percentage of equity financing differs based on the amount of fundraising where the percentage is lower for a larger amount and higher for the smaller amount.

Though the percentage of fundraising costs for both debt and equity financing are similar, the key to financing options depends on the overall condition of the business. Firstly, the equity financing option best suits the SMEs that maintain proper documents in dealing its business or operations, and the possession of assets that comprises the organization's paid-up capital in the name of the firm. On the contrary, debt capital may be the best option for the unorganized firms that do not maintain proper tax documentation or books of accounts; and for those that do not have the assets registered in the name of the firm. However, repayment of the installments along with interest is one of the greatest drawbacks of debt financing since the firm has to start repayment before utilizing the funds or receiving positive turnover from the fund. Even, the bank and FIs deduct the first installment at source before allotment of funds. However, the best financing option depends on the costs and time associated with documentation, asset conversion and getting listed in the Exchange versus stamp duty, interest rate, loan processing charges, collateral requirements and time associated with getting credit from banks or FIs.

\subsection{Time Required for Fund Raising and Listing}

It is estimated that the SMEs can avail the fund by getting listed in the SCP in 170 days (DSE SME 2019b). However, the estimation leaves 50 days for preparing the prospectus, supporting documents and getting approval from the BoDs of the concerned issuer. The great concern arises whether the SMEs can prepare the documents and submit the application within this period. In general, if the SMEs are prepared enough in terms of documentation, books of accounts, asset valuation and asset conversion, they can easily apply within the prescribed period to get the fund within the next 3 months. On the contrary, if the SMEs are not prepared enough, it may require 6 to 12 months to complete the documentation and prospectus preparation process. For this reason, the unorganized SMEs requires to wait for a significant period for getting funds by issuing securities in the capital market.

\section{Initiatives Taken by the Regulators to Remedy the Obstacles}

\subsection{Cost Minimization}

SMEs operate their business by using a limited amount of resources. In this regard, cost minimization is the core mechanism for most of the SMEs. If they incur higher costs of fundraising, they cannot effectively attain their objectives. For this instance, the Exchange and BSEC impose the least degree of cost burden for listing and getting funds. The Exchange only asks for prospectus scrutiny fee of BDT 25,000 and listing fee at the rate of $0.0125 \%$ for the first $100 \mathrm{mn}$ and $0.075 \%$ for the rest of the QIO amount (DSE 2019).

BSEC only requires application fee and consent fee. The cost minimization initiative of BSEC is presented 
in the following table;

Table 2: Cost minimization initiative of BSEC

\begin{tabular}{|l|l|l|}
\hline \multicolumn{1}{|c|}{ Particulars } & \multicolumn{1}{c|}{ QIO Rules, 2016 } & \multicolumn{1}{c|}{ QIO Rules, 2018 } \\
\hline Application fee for BSEC & BDT 10,000 & BDT 5,000 \\
\hline Consent fee for BSEC & BDT 50,000 & BDT 10,000 \\
\hline
\end{tabular}

Source: BSEC (2019)

The above table illustrates that BSEC has deducted the application fee by $50 \%$ and the consent fee by $80 \%$. Since the SMEs generally asks for a minimal amount of fund considering their existing capital, higher costs for application and consent fee will eventually discourage the SMEs. Hence, the commission demands the least amount of money from the SMEs so that they enthusiastically participate in the SCP.

\subsection{Risk Minimization}

Compared to the large corporations, the MSMEs are very much vulnerable in terms of capital adequacy, utilization of funds, growth opportunities, ROI and sustainability. The failure rate of SMEs is significantly higher than the large corporations. For this instance, the SME platform possesses greater risks than the mainboard. The retail investors of the capital market experience divesting losses in case of market downturn. By considering the risk factors, the BSEC and Exchange of the country have formulated several mechanisms to discourage the participation of very retail investors in the SME platform. The primary reason for discouraging retail investors is that they have minimal risk-taking capacity than institutional investors. Besides, the retail investors do not have enough financial literacy to project the highly risky business pattern like that of SMEs. According to section 2(f) of BSEC (QIO by SCC) Rules, 2018, only the Qualified Investors (QIs) can participate in the primary market of SCP. The QIs include Eligible Investors (EIs), market makers, issuer of listed securities and high net worth individuals having a minimum net worth of BDT 10mn (BSEC 2019). EIs comprises the merchant bankers, investment bankers, insurance companies, asset managers and so on institutions. By restricting the participants in the primary market, the BSEC and Exchange have ensured the participation of institutional and knowledge investors.

All types of investors can participate in the secondary market of SCP but there is also a restriction: the minimum contract value of the trade is $0.2 \mathrm{mn}$ BDT (DSE 2019). Hence, by default, the secondary market of SCP is basically a block market in nature. Chiefly, this limitation assures that investors cannot participate in the SCP with a lower amount of investment as trade value below BDT $0.2 \mathrm{mn}$ has no window for trading except in the oddlot market, which is not a designated formal market. In result, the market will experience a viable turnover in trade in bulk volume with the participation of quality investors who can take greater degree of risks.

\subsection{Removal of Legal Limitations}

Initially BSEC (QIO by SCC) Rules, 2016 was published for the operations and regulations of SCP. However, after analyzing the rules in the light of the limitations of the SMEs, a new rule named BSEC (QIO by SCC) Rules, 2018 has repealed the previous one on January 30, 2019. In the modified rules, the BSEC, the law-making authority of the capital market of Bangladesh, has relaxed certain clauses and introduced few new clauses for the smooth operations of the platform considering the practical situation of the SMEs.

6.3.1 Relaxation of Corporate Governance Code

According to Section-13 of QIO Rules, 2016, the SMEs had to comply the Corporate Governance Code (CGC) prescribed by BSEC like the large corporations listed on the main board of the Exchange (BSEC 2016). However, BSEC has relaxed the requirement of complying CGC for companies listed in the SCP in QIO Rules, 2018. In this case, these companies are considered as learners of corporate governance so that they can effectively exercise governance issues in the future after migrated to the mainboard.

Subject to the fulfilment of other conditions, the SMEs can avail the opportunity to migrate to the mainboard after reaching the post-issue paid-up capital of BDT 300mn (BSEC 2019). Once the SMEs are migrated to the mainboard, they must fully comply the CGC of BSEC and the Exchange. For this reason, the SCP platform provides a learning window that will educate the SMEs to exercise some sort of disclosure and reporting issues to get them prepared for the strict compliances of the mainboard.

6.3.2 Relaxation of Minimum Capital Requirement

According to the QIO Rules, 2016, the minimum pre-issue paid-up capital was set as BDT 50mn, while a SME had to raise at least BDT 50mn through QIO. Hence, the post-issue paid-up capital would be at least BDT 100mn. In the existing QIO Rules, 2018, there is no such lower limit of pre-issue paid-up capital for the fixed price method. However, there is still a limit of minimum BDT 100mn for the book-building pricing method. As per the initial rules, the minimum post-issue paid-up capital must be BDT $100 \mathrm{mn}$, while in the existing rules the post-issue paidup capital must be between BDT 30mn and BDT 300mn. Hence, the previous rules had restricted many SMEs having less than BDT 50mn pre-issue paid-up capital. The new rules have abolished these two clauses so that more companies can have the opportunity to get listed in the Exchange and raise funds through the SCP. 
A comparison of BSEC (QIO by SCC) Rules, 2016 and BSEC (QIO by SCC) Rules, 2018 regarding pre-issue and post-issue capital requirement is as follows;

Table 3: Comparison of capital requirement for Fixed Price (FP) and Book-Building Price (BB) method

\begin{tabular}{|l|l|l|l|}
\hline \multicolumn{1}{|c|}{ Particulars } & \multicolumn{1}{|c|}{ QIO Rules, 2016 } & \multicolumn{1}{c|}{ QIO Rules, 2018 } & \multicolumn{1}{c|}{ Comment } \\
\hline $\begin{array}{l}\text { Pre-issue paid-up capital } \\
\text { (Minimum) }\end{array}$ & FP: BDT 50mn & FP: 15mn BDT & Made flexible \\
\cline { 2 - 4 } $\begin{array}{l}\text { Post-issue paid-up capital } \\
\text { (Minimum) }\end{array}$ & BB: BDT 100mn & BB: BDT 100mn & No change \\
\cline { 2 - 4 } $\begin{array}{l}\text { Post-issue paid-up capital } \\
\text { (Maximum) }\end{array}$ & BB: BDT 150mn & FP: BDT 50mn & Made flexible \\
\hline Auditing standards & $\begin{array}{l}\text { Bangladesh Standards on } \\
\text { Auditing (BSA) }\end{array}$ & $\begin{array}{l}\text { International Standards on } \\
\text { Auditing (ISA) }\end{array}$ & $\begin{array}{l}\text { Ensured global } \\
\text { standards }\end{array}$ \\
\hline \begin{tabular}{l} 
Appointment $\begin{array}{l}\text { Bund } \\
\text { maker }\end{array}$ \\
\hline
\end{tabular} & $\begin{array}{l}\text { For at least 3 years after } \\
\text { listing }\end{array}$ & No such clause & Relaxed \\
\hline
\end{tabular}

Source: BSEC (2019)

Note: *Though there is no requirement for pre-issue paid-up capital for FP, there is a provision for holding at least $30 \%$ of the total share by the sponsor(s)/director(s) of the firm. Considering the minimum post-issue paid-up capital, the pre-issue paid-up capital must not be less than $15 \mathrm{mn}$.

6.3.3 Relaxation of Reporting and Disclosure Obligations

Unlike the strict reporting and disclosure obligations of the mainboard, the SCP requires the most simplified form of compliance issues. The primary purpose of this relaxation is to attract the small and medium entrepreneurs without producing any significant burden or troublesome situation of paperwork, and rigorous monitoring. Chiefly, the SMEs fight for efficient operation of their regular business function with limited resources. If the Exchange or BSEC puts strict burden of paperwork for regular reporting like the mainboard, the SMEs will be discouraged while they have already the fear of reporting and compliance issues of the capital market.

Here is a comparison of mainboard and the SCP regarding the disclosure and reporting compliances;

Table 4: Reporting and disclosure requirements of mainboard and SCP

\begin{tabular}{|l|l|l|}
\hline \multicolumn{1}{|c|}{ Issues of Reporting and Disclosure } & \multicolumn{1}{c|}{ Main Board } & \multicolumn{1}{c|}{ SCP } \\
\hline Shareholding and free-float position & Monthly & Half-yearly \\
\hline Submission of audited financial statements & Quarterly and Annually & Annually \\
\hline $\begin{array}{l}\text { Declaration by sponsor(s) or director(s) before buy } \\
\text { and/or sale of ordinary shares }\end{array}$ & Yes & Yes \\
\hline $\begin{array}{l}\text { Real-time publication of Price Sensitive Information } \\
\text { (PSI) }\end{array}$ & Yes & Yes \\
\hline
\end{tabular}

SOURCE: DSE (2019)

The above table implies that the BSEC and Exchange have followed 'Go Easy' principle for SMEs. A company listed in the main board of the Exchange has to report free-float and shareholding position of the sponsors, directors and investors who hold more than $10 \%$ of the paid-up capital on a monthly basis (DSE 2019). On the contrary, monthly reporting may irritate the SMEs considering their availability of resources. Furthermore, quarterly submission of audited financial statements may produce excessive costs for SMEs. For these reasons, the reporting and disclosure requirements have relaxed for the SMEs so that they are in a comfort zone in the capital market environment. However, sponsors' or directors' declarations before buy or sale of shares and publication of PSI are made mandatory considering the transparency and investor's rights.

\subsection{Investor's Protection}

Considering the SME platform as a highly risky market, the Exchange and BSEC must ensure that the investors have provided with ultimate fairness and transparency in their engagement with SMEs. Investors must have the confidence that they are provided with the safest possible ground for their investment. The regulators have already introduced several rules, regulations and mechanisms to bring investors' confidence, ensure transparency and protect investors' rights.

Firstly, the sponsors' or directors' ordinary shares will be locked-in for at least a year (DSE 2019). They are not allowed to buy or sale of securities without any prior declaration. Furthermore, no company is allowed to issue more than $70 \%$ of the post-issue paid-up capital (DSE SME 2019a). Hence, the sponsors and/or directors of the business must hold at least $30 \%$ of the total post-issue paid-up capital throughout the lifespan in the SCP. These rules will prevent fraudulent activates of the sponsors and directors after raising capital by issuing securities to the public. For these mechanisms, they will also be accountable for efficient business operations for their own claim to the business.

Secondly, the issue manager(s) cannot be connected in any way with the issuer. The manager of the issue is 
also prohibited from holding any of the concerned SME's securities or apply for new subscriptions on the concerned issue. Moreover, no connected person or related party of the issuer is considered as qualified to participate in the bidding process of the concerned offer. These restrictions will ensure that the recommendations made by the issue manager(s) are authentic and transparent, and the issuer is in no way connected with the manipulation of the transparent securities allocation process. However, if the issue managers or the issuer engages in any fraudulent activities during the QIO process, the BSEC has several other legal jurisdictions to remedy the situation.

Thirdly, for QIO, 50\% of the issue must be underwritten, while the percentage of underwritten value must be $100 \%$ for repeat QIO (BSEC 2019). The regulators have imposed this restriction so that the risks of undersubscription can be bypassed and costs associated with under-subscripted QIO can be minimized.

Finally, no single investor, either individual or institution, is allowed to apply for more than $10 \%$ of the QIO amount. This will reduce the possible threat of manipulation, hostile takeover of business or force alternation of the Board of Directors (BoDs).

\section{Prospects of SCP and SMEs in SCP}

The failure rate of SMEs in the capital market is relatively high as compared to large corporations. For example, Bombay Stock Exchange has listed 330 small and medium-sized companies in its SME window (Bombay Stock Exchange [BSE] n.d.). Among them, 97 are successfully migrated to the mainboard, and the remaining 237 companies are eligible for trading activities. However, about 70 to 80 companies remain active in regular trading (BSE n.d.). Among the active companies, the share price of more than 10 companies has gone below the face value. Though the failure rate is high, the successful one brings a great positive difference in the capital market situation. For example, about $40 \%$ of the market capitalization of Shenzhen Stock Exchange is SME based; and the Exchange has a unique grip in the world capital market (Shenzhen Stock Exchange n.d.). Considering the performance of the capital market and economy of Bangladesh, the SCP may not share a significant portion of total market capitalization. However, due to the relaxed listing requirements and least degree of compliance, it will have a great influence on attracting potential companies to be listed in the SME and, eventually, to the mainboard. As a result, the number of participants in the capital market will increase a great extent.

SCP is the experimental field to define the future potential of SMEs in the capital market arena in Bangladesh. Once a company performs well in SCP and grown gradually to be listed on the main board of the Exchange, it is projected that these SCP tested entities will not fail in the main market situation. Chiefly, the companies that perform well in the SCP for a significant period will make a significant difference to stabilize the capital market of the country.

SCP will surely introduce a dramatic milestone in the history of the capital market of Bangladesh. Since the introduction of Exchange in the country, the capital market entirely depends on the large corporations without any learning ground. For this reason, after engaging with the Exchange, a corporation had to experience devastating trouble to comply the CGC, disclosure obligations and reporting issues. Due to the introduction of the learning platform, the Exchange can ensure optimum investor rights by addressing the corporate governance compliances more effectively. At present, the capital market facilitates a learning platform for the SMEs, which have a great growth potential to be enlisted with the main platform of the Exchange in future.

The capital market of Bangladesh has introduced a new window for financing the small and medium scale public limited companies for the very first time. On one hand, the SMEs will get a new formal financing platform. On the other hand, they will learn about the standard corporate culture and good governance, which are essential for listed corporations. Hence, SCP opens a new door for financing small and medium entities to grow and helps them to be socially responsible.

The introduction of formal SME financing through the capital market will reduce extreme dependency on commercial and specialized banks. In turn, the credit pressure on banks will significantly reduce; and the banks can utilize those resources in investment projects to other potential sectors that require quality financing. It also escalates access to formal SME financing and reduces a great extent of the existing deficit. Usually, Banks and FIs cannot sanction a large amount of loan without availing guarantee or collateral worth such amount. Thus, the SCP will be the primary ground for large scale of financing without demanding any security deposit if the organization can satisfy the investors about its growth potentials.

Sustainability is a burning question of the country's capital market. Trained and tested corporations can play a pivotal role in making a sustainable capital market. As the SME platform is the learning and performing field for the small and medium companies, the good learners and good performers-once migrated to the mainboard-may bring a noteworthy positive outcome to institute a sustainable secondary market. In addition, today's competitive world believes in sustainable growth and continuous development for long-term survival (Keller 2009). The existing formal financing windows-Banks and FIs $\neg$ mostly sanction short-term credit to the SMEs. For this reason, corporations that are planning for perusing long-term business potentials will find it fascinating to engage with the capital market for higher corporate value, higher credibility to the stakeholders and superior brand image. Once 
the stakeholders are well informed about its benefits in near future, the SME platform will be the space-station for the aspirants to kick-off beyond the horizon.

In the era of e-commerce, small and medium corporations can provide services across the country like large corporations. To capitalize this opportunity, the SMEs must be known to the customers and related stakeholders. The customers do not feel comfortable receiving services from unknown sources. For this reason, the SMEs may have the access across the country, but they cannot effectively cash the opportunity. The capital market platform can deliver the window to the SMEs for integrated public appearance through ensuring the obligation of disseminating financial information to the public. In addition, listed companies attain more media coverage after publishing financial accounts, PSI, board meeting, dividend declaration and so on. The listed companies can interact with the stakeholders more easily by using the stock exchange platform. For this reason, it is projected that once the SMEs understand the benefits of branding through public appearance, more and more SMEs will be encouraged to be listed in the SCP.

\section{Conclusion}

The SME sector is one of the primary actors of a country's GDP and employment. Despite their importance, the SMEs across the globe have restricted formal financing opportunities. Either the creditors are not interested enough to finance the SMEs instead of large corporations or the SMEs cannot satisfy all the financing requirements especially collateral. Bangladesh also experiences a significant deficit of SME financing. The SCP will not only reduce the financing gap but also facilitate a learning ground where the SMEs can exercise good governance and standard corporate culture. The SCP will also ensure long-term growth and sustainable development of SMEs by articulating the demand for long-term financing with lower costs. The learnings of corporate governance and compliance issue from the SCP will successfully satisfy the strict compliance issues of the capital market in the future. Once migrated from the SCP to the mainboard, these tested companies are projected to be the failsafe corporations of the capital market. In turn, the SCP will contribute a great extent to establish a sustainable capital market with transparency and good governance.

\section{References}

Abdullah, S.F. (2019), "Market Promotion and Investor Education Tailored for SME Market in Bangladesh", International Seminar on Capital Market for SMEs, Shenzhen: Shenzhen Stock Exchange, 47-52.

Alauddin, M., \& Chowdhury, M.M. (2015), "Small and Medium Enterprise in Bangladesh-Prospects and Challenges", Global Journal of Management and Business Research 15(7), 1-10.

Agwu, M.O. (2014), "Issues, Challenges and Prospects of Small and Medium Scale Enterprises (SMEs) in PortHarcourt City", European Journal of Sustainable Development 3(1), 101-114. https://doi:10.14207/ejsd.2014.v3n1p101

Ahmed, M.U. (2001), "Globalisation and Competitiveness of Bangladesh's Small Scale Industries (SSIS): An Analysis of the Prospects and Challenges", Bangladesh Facing the Challenges of Globalisation, 2-5.

Amyx, C. (2005), “Small Business Challenges- The Perception Problem: Size Doesn't Matter", Washington Business Journal, 5.

Bangladesh Bank. (n.d.), "Small and Medium Enterprise (SME) Credit Policies \& Programmes". Available at: https://www.bb.org.bd/sme/smepolicye.pdf

Bangladesh Securities and Exchange Commission. (2019), "Bangladesh Securities and Exchange Commission (Qualified Investor Offer by Small Capital Companies) Rules, 2018". Available at: https://www.sec.gov.bd/slaws/Bangladesh_Securities_and_Exchange_Commission_(Qualified_Investor_Of fer_by_Small_Capital_Companies)_Rules,_2018.pdf

Bangladesh Securities and Exchange Commission. (2015), "Bangladesh Securities and Exchange Commission (Public Issue) Rules, 2015”. Available at: https://sec.gov.bd/lbook/F-07_2015.pdf

Basil, A.N.O. (2005), "Small and Medium Enterprises (SMES) in Nigeria: Problems and prospects", Ph.D. Thesis, St. Clements University. Available at: http://stclements.edu/grad/gradonug.pdf

Beck, T., \& Cull, R. (2014), "Small and Medium-Sized Enterprise Finance in Africa", African Growth Initiative (working paper 16), Washington DC: Brookings

Bombay Stock Exchange. (n.d.), "Market Statistics". Available at: https://m.bseindia.com/smemarket.aspx (Accessed 25 December 2020)

Dhaka Stock Exchange. (n.d.), "DSE Data Archive". Available at: https://www.dsebd.org/market summary.php?startDate=2018-12-09 (Accessed 09 December 2020)

DSE. (2019), “Dhaka Stock Exchange (Listing of Small Capital Companies) Regulations, 2019”. Available at: https://www.dsebd.org/sme/Regulations/SME\%20Regulations.pdf (Accessed 21 December 2020)

DSE SME. (2019a), "Shareholding Condition and Lock-in Period". Available at: https://www.dsebd.org/sme/corporates-lock-in-period (Accessed 21 December 2020)

DSE SME. (2019b), "Tentative Time Schedule for Offer under Fixed Price Method". Available at: 
https://www.dsebd.org/sme/corporates-time-schedule.htm Accessed 21 December 2020)

Hasan, F., \& Jamil, G.M. (2014), "Financing Small and Medium Enterprises in Bangladesh-Issues and Challenges". The Asian Journal of Technology Management, 7(1), 45-54. https://doi:10.12695/ajtm.2014.7.1.5

Islam, M.N., Arefin, K., \& Hossain, M.M. (2005), "Small Business Financing: Problems Analysis and Overcome Strategies", Journal of Business Research, 7(June), 1-102.

Keller, R. (2009, January 11), “Continuous improvement-Taking the long-term perspective will pay off”, Industry Week. Available at: https://www.industryweek.com/the-economy/article/21938524/continuousimprovement-taking-the-longterm-perspective-will-pay-off (Accessed 24 December 2020)

Ministry of Commerce. (n.d.), "Companies act, 1994”, Government of the People's Republic of Bangladesh. Available at: https://www.iiiglobal.org/sites/default/files/companiesact_0.pdf

Ministry of Industries. (2016), "National Industrial Policy, 2006”, Government of the People's Republic of Bangladesh. Available at: https://moind.portal.gov.bd/sites/default/files/files/moind.portal.gov.bd/policies/55dad52c_913d_487d_b59 a_26db59742b49/Industry\%20Policy\%202016\%20Scan\%20Copy.pdf

Muriithi, S.M. (2017), “African Small and Medium Enterprises (SMEs) Contributions, Challenges and Solutions”, European Journal of Research and Reflection in Management Sciences, 5(1), 36-48.

Rogers, B.A. (2002), "Funding of SMEs: Sourcing of Funds and Problems Limiting Access", ICANjournal, 35(1), 15-18.

Shenzhen Stock Exchange. (n.d.), "Market overview”. Available at: http://www.szse.cn/English/ (Accessed 25 December 2020)

SME Foundation. (2019), "Women Entrepreneurs in SMEs: Bangladesh Perspective 2017”, Small and Medium Enterprise Foundation. $\quad 2-110 . \quad$ Available at: https://smef.portal.gov.bd/sites/default/files/files/smef.portal.gov.bd/files/4937b241_2c1c_44d4_9e8b_e5bb 81dcec12/91652a939071e2a55ad54299007166d5.pdf

Star Business Report. (2019, September 30), "SME Contribution Still Negligible: Study", The Daily Star. Available at: https://www.thedailystar.net/business/news/sme-contribution-still-negligible-study-1807207 (Accessed: 16 September 2020)

The Finance Today. (2020, July 05), "Reduced Registration Fee For Land, Flat To Be Effective From Today", The Finance Today. Available at: https://www.thefinancetoday.net/article/national/12622/Reduced-registrationfee-for-land-flat-to-be-effective-from-today (Accessed 21 December 2020)

The World Bank. (n.d.), "Long Term Finance". Available at: https://www.worldbank.org/en/publication/gfdr/gfdr-2016/background/long-term-finance (Accessed 22 December 2020)

Uddin, M.I. (2019, December 24), "SMEs in Promoting Sustainable Growth”, The Financial Express. Available at: https://thefinancialexpress.com.bd/views/smes-in-promoting-sustainable-growth-1576305701 (Accessed: 16 September 2020)

Uddin, M.T. (2014), “A Study on Financing of SME's in Bangladesh”, Journal of Economics and Sustainable Development, 5(11), 161-167.

World Bank Group. (2019), "Finance, Competitiveness \& Innovation Insight | Financial inclusion, infrastructure \& access", The World Bank Group, 1-64.

Xiaojin, T. (2019), "Market Promotion and Investor Education Tailored for SME Market in Bangladesh". International Seminar on Capital Market for SMEs, Shenzhen: Shenzhen Stock Exchange, 7-15. 